\title{
BMJ
}

\section{Integrated motivational interviewing and cognitive behavioural therapy for people with psychosis and comorbid substance misuse: randomised controlled trial}

\author{
Christine Barrowclough, professor of clinical psychology, ${ }^{1}$ Gillian Haddock, professor of clinical psychology, \\ Til Wykes, professor of clinical psychology and rehabilitation, ${ }^{2}$ Ruth Beardmore, trial manager, ${ }^{1}$ Patricia \\ Conrod, senior lecturer, ${ }^{2}$ Tom Craig, professor of community and social psychiatry, ${ }^{2}$ Linda Davies, professor \\ of health economics, ${ }^{3}$ Graham Dunn, professor of biomedical statistics, ${ }^{3}$ Emily Eisner, research associate, ${ }^{1}$ \\ Shôn Lewis, professor of adult psychiatry, ${ }^{3}$ Jan Moring, consultant clinical psychologist, ${ }^{4}$ Craig Steel, senior \\ lecturer, ${ }^{5}$ Nicholas Tarrier, professor of clinical psychology'
}

\begin{abstract}
School of Psychological Sciences, University of Manchester, Manchester, UK

${ }^{2}$ King's College London, London, UK

${ }^{3}$ School of Community Based Medicine, University of Manchester, Manchester

${ }^{4}$ Substance Misuse Directorate, Greater Manchester West Mental Health NHS Foundation Trust, Prestwich, UK

${ }^{5}$ School of Psychology and Clinical Language Sciences, University of Reading, Whiteknights, Reading,

Correspondence to: $\mathrm{C}$

Barrowclough

christine.
\end{abstract} UK

barrowclough@manchester.ac.uk

Cite this as: BMJ 2010;341:C6325 doi:10.1136/bmi.c6325

\section{ABSTRACT}

Objectives To evaluate the effectiveness of integrated motivational interviewing and cognitive behavioural therapy in addition to standard care for patients with psychosis and a comorbid substance use problem. Design Two centre, open, rater blind randomised controlled trial.

Setting Secondary care in the United Kingdom.

Participants 327 patients with a clinical diagnosis of schizophrenia, schizophreniform disorder, or schizoaffective disorder and a diagnosis of dependence on or misuse of drugs, alcohol, or both according to the Diagnostic and Statistical Manual of Mental Disorders, fourth edition.

Intervention The intervention was integrated motivational interviewing and cognitive behavioural therapy plus standard care, which was compared with standard care alone. Phase one of therapy-"motivation building"concerns engaging the patient, then exploring and resolving ambivalence for change in substance use. Phase two-"action"-supports and facilitates change using cognitive behavioural approaches. Up to 26 therapy sessions were delivered over one year.

Main outcome measures The primary outcome was death from any cause or admission to hospital in the 12 months after completion of therapy. Secondary outcomes were frequency and amount of substance use (assessed using the timeline followback method), readiness to change, perceived negative consequences of use, psychotic symptom ratings, number and duration of relapses, and global assessment of functioning and deliberate self harm at 12 and 24 months, with additional timeline followback assessments at 6 and 18 months. Analysis was by intention to treat and robust treatment effect estimates were produced.

Results 327 participants were randomly allocated to either the intervention $(n=164)$ or treatment as usual $(n=163)$. At 24 months, 326 (99.7\%) were assessed on the primary outcome and $246(75.2 \%)$ on the main secondary outcomes. Treatment had no beneficial effect on hospital admissions or death during follow-up, with $23.3 \%(38 / 163)$ of the therapy group and $20.2 \%$ (33/ 163) of controls deceased or admitted (adjusted odds ratio $1.16,95 \%$ confidence interval 0.68 to 1.99 ; $\mathrm{P}=0.579$ ). Therapy had no effect on the frequency of substance use or the perceived negative consequences of misuse, but did have a statistically significant effect on amount used per substance using day (adjusted ORs for main substance $1.50,95 \% \mathrm{Cl} 1.08$ to $2.09 ; \mathrm{P}=0.016$; and all substances $1.48,95 \% \mathrm{Cl} 1.07$ to $2.05 ; \mathrm{P}=0.017$ ). Treatment had a statistically significant effect on readiness to change use at 12 months (adjusted OR 2.05, $95 \% \mathrm{Cl} 1.26$ to $3.31 ; \mathrm{P}=0.004)$ that was not maintained at 24 months $(0.78,95 \% \mathrm{Cl} 0.48$ to $1.28 ; \mathrm{P}=0.320)$. There were no effects of treatment on clinical outcomes such as relapses, psychotic symptoms, functioning, and self harm.

Conclusions Integrated motivational interviewing and cognitive behavioural therapy for people with psychosis and substance misuse do not improve outcome in terms of hospitalisation, symptom outcomes, or functioning. This approach does reduce the amount of substance used for at least one year after completion of therapy.

Trial registration Current Controlled Trials: ISRCTN14404480.

\section{INTRODUCTION}

People with psychosis have much higher rates of problem alcohol and illicit drug use than the general population. The United States Epidemiologic Catchment Area study calculated that the odds of having an alcohol or drug disorder for people with a diagnosis of schizophrenia were three and six times higher than for the general population, respectively. ${ }^{1}$ In the United Kingdom, the prevalence of co-occurring substance misuse in past year among people with psychosis is estimated at around $25 \% .^{23}$ These dual problems are associated with many illness complications, including increased 
severity of symptoms, suicide, poorer compliance with treatment, non-adherence to medication, more hospitalisations, violence, homelessness, and victimisation. ${ }^{45}$

A Cochrane review of psychosocial interventions for people with both severe mental illness and substance misuse identified 25 studies. ${ }^{6}$ The authors concluded that there is no compelling evidence to support any one psychosocial treatment to reduce substance use or to improve mental state in this patient group. They also identified major problems in the studies conducted, including small heterogeneous samples, flawed experimental designs, high attrition rates, and short follow-up periods.

Although the evidence base is limited, key elements have been recommended for treatments that aim to reduce substance use and thereby improve outcomes. ${ }^{78}$ These include, firstly, ensuring that both mental health and substance use problems are given attention in an integrated approach and, secondly, addressing patients' motivation to reduce substance use. Given that motivation to reduce substance use is often low in such patients, ${ }^{910}$ motivational interventions, and in particular motivational interviewing, ${ }^{11}$ have also been recommended. Motivational interviewing has a good evidence base with regard to promoting health behaviour change, ${ }^{12}$ including in treatment for substance misuse. ${ }^{13}$ An additional approach commonly used is cognitive behavioural therapy, because it is efficacious for both primary substance misuse disorders ${ }^{14-16}$ and psychotic symptoms. ${ }^{17} 18$

We have previously reported a small sample size randomised controlled trial that evaluated a nine month individual treatment consisting of motivational interviewing plus individual and family cognitive behavioural therapy for patients with schizophrenia and comorbid substance misuse. ${ }^{10}{ }^{19}$ At 12 months, the treatment was superior to standard care provided by mental health services in terms of patients' general functioning, positive symptoms (excess or distortion of normal functioning, such as delusion and hallucinations), symptom exacerbations, and frequency of substance use. Some gains were lost at the 18 month follow-up, although improvement in general functioning was maintained and the experimental group showed improved negative symptoms (diminution or loss of normal functions, such as affective flattening, anhedonia, and attentional impairment) at 18 months.

We aimed to conduct a full scale randomised controlled trial to determine the efficacy of integrated motivational interviewing and cognitive behavioural therapy delivered by trained therapists in addition to mental health services standard care. On the basis of the findings of our previous study, a number of changes were made to the therapy and study design. For example, there was increased emphasis on facilitating motivation, given the low levels of motivation for change in our first study. To increase the generalisability of our findings, the study included patients without carers and therefore excluded the family component of the intervention. The treatment period was extended to 12 months to allow more time for patients to participate in therapy, given that the lifestyles of some participants made regular appointments difficult, missed appointments inevitable, and periods of disengagement common.

\section{METHODS}

The trial was overseen by independent data monitoring and trial steering committees and is reported in accordance with the CONSORT guidelines for non-pharmacological trials. ${ }^{20-22}$ Ethical approval was obtained from the Cambridgeshire 4 research ethics committee (formerly the eastern multicentre research ethics committee; reference 03/5/045). All participants gave written informed consent before taking part.

\section{Participants}

Between October 2004 and April 2007 research teams in two centres (Manchester and London) recruited participants from adult services in six large NHS mental health trusts in the UK covering Greater Manchester, Lancashire, and south London. Inclusion criteria were the following: age more than 16 years; in current contact with mental health services; a current clinical diagnosis of non-affective psychotic disorder (international classification of diseases, 10th revision (ICD-10), Diagnostic and Statistical Manual of Mental Disorders, fourth edition (DSM-IV), or both); DSM-IV diagnosis of dependence on or abuse of drugs, alcohol, or both; minimum level of weekly alcohol use (exceeding 28 units for males and 21 units for females on at least half the weeks in the past three months) or illicit drug use (use on at least two days a week in at least half the weeks in the past three months); no significant history of organic factors implicated in the aetiology of psychotic symptoms; English speaking; and of a fixed abode (including bed and breakfast or hostel).

\section{Procedure}

Potential participants were identified by care coordinators. Where case notes confirmed diagnostic eligibility, a research assistant asked potential participants to complete a checklist of substances used and describe typical alcohol and drugs use in the past three months. Patients meeting inclusion criteria for levels of alcohol use, illicit drug use, or both completed the alcohol and drug sections of the structured clinical interview for the DSM-IV, as appropriate. ${ }^{23}$ If patients used more than one illicit drug, the assessment was administered for the drug perceived by the participant to be most problematic or, if the person did not make such a distinction, the most frequently used. If dependence or abuse criteria were not met for this drug, the assessment was repeated for the next most problematic drug until criteria were met. Those not meeting DSM-IV dependence or abuse criteria for alcohol or an illicit drug were not eligible to participate in the trial.

After screening, participants were assessed for baseline measures. Random allocation to therapy plus standard care or standard care alone was performed using a remote independent service, with a minimisation algorithm taking into account substance type (alcohol 
alone, drugs alone, or alcohol and drugs), main drug of use (cannabis, amphetamines, opiates, or other), and NHS trust.

\section{Intervention}

The psychological therapy consisted of up to 26 individual therapy sessions delivered over 12 months at the patient's location of choice, which was usually their home. Where patients consented, therapy sessions were audiotaped for therapist supervision and evaluation of treatment fidelity. The therapy was delivered in accordance with the detailed manual, available from the corresponding author and described elsewhere. ${ }^{24}$

Considerable emphasis was placed on initiating and maintaining engagement in therapy with strategies such as brief initial visits with conversation based on the patient's interests for those reluctant to engage; identifying lifestyle change as the key therapy target so as not to engender resistance in those with low motivation to reduce substance use in the initial stages of the intervention; rescheduling of missed appointments; flexibility in timing and location of sessions; and tracking of change in residence.

Treatment was built around two phases to allow motivational interviewing and cognitive behavioural therapy to be integrated without compromising the essential spirit and fundamentals of each approach. Phase one of the intervention-"motivation building"-selectively elicited and reinforced "change talk" through use of the core skills and principles of motivational interviewing. ${ }^{11}$ The following stages were used: engagement; eliciting and understanding the patient's perspective in relation to life goals; and exploring the patient's perspectives on both substance misuse and mental health issues in relation to goals. Information and feedback from assessments was incorporated into these stages using a motivational style to support formulation of a shared understanding in relation to the person's concerns, substance misuse, and mental health difficulties. This was used to further develop ambivalence and consolidate motivation for changing substance use.

In phase two of the intervention, a plan for change was developed. Where the person was open to change in substance use, cognitive behavioural techniques from both the psychosis and substance use evidence base were used to formulate a change plan and to help the patient implement and maintain changes such as reduction or abstinence in one or more substances. Components included identifying and increasing awareness of high risk situations and warning signs for substance use lapse or relapse; developing coping skills for handling such situations, with particular attention to psychosis symptoms and mental health problems highlighted in formulation (for example, strategies for dealing with distressing voices or with depressed mood); coping with cravings and urges; making lifestyle changes as alternatives to substance use; and normalising and responding to lapses and relapses. For those who did not identify substance use as problematic, the intervention was sufficiently flexible to allow therapists to work with other patient led problems. In such cases, the therapist would use motivational interviewing techniques to help the patient to link substance use to their concerns. Three liaison meetings between the patient, the therapist, and the patient's case manager were scheduled during therapy to communicate progress.

Standard psychiatric care in the UK comprises antipsychotic medication, outpatient and community follow-up, and access to community based rehabilitative activities. To reduce variation among the clinical teams with regard to access to substance misuse services, we provided a handbook containing brief guidelines on managing people with psychosis and substance misuse, including information on medication and a directory of local resources.

\section{Training and monitoring trial therapists}

The trial therapists were two clinical psychologists, two nurse therapists, and one social worker, who all had training and experience in conducting cognitive behavioural therapy with people who have psychosis. During a three month period before seeing trial participants, therapists undertook training in motivational interviewing, cognitive behavioural therapy for substance misuse, and integrated motivational interviewing and cognitive behavioural therapy, with all therapists practising the integrated therapy with volunteer patients under supervision. Weekly group and individual supervision were provided while the therapists were treating trial participants.

Treatment fidelity and quality were assessed in supervision via listening to the therapy audiotapes and discussion of cases, with frequent reference to the therapy manual. Additionally, an independent rater with experience in delivering motivational interviewing and cognitive behavioural therapy assessed a sample of 40 audiotaped therapy sessions, each from a different participant, that were randomly selected from the pool of 1248 audiotaped sessions. The rater used a fidelity scale designed to assess integrated motivational interviewing and cognitive behavioural therapy. ${ }^{25}$ This scale consists of 16 items, each rated as "compliant" or "not compliant," that were generated from the treatment protocol and used to facilitate assessment of therapy content and structure, and the core skills of the therapist. The scale has good inter-rater reliability and validity.

\section{Assessment of outcomes}

Demographic information and duration of psychosis and substance misuse were collected at baseline via self report. The alcohol use disorders identification test $^{2627}$ and the drug misuse screening test ${ }^{2829}$ assessed severity of use. The drug attitude inventory was used as a proxy measure for compliance with prescribed antipsychotic medication. ${ }^{30}$

For outcomes requiring self reports, research assistants blind to treatment allocation assessed participants at baseline, after completion of treatment (12 months), 
Table 1|Baseline demographics and psychiatric and substance use history

\begin{tabular}{|c|c|c|}
\hline & Control $(n=163)$ & Therapy $(n=164)$ \\
\hline Age (mean (SD)) & $38.3(10.0)$ & $37.4(9.4)$ \\
\hline Gender (n male (\%)) & $137(84.0)$ & $146(89.0)$ \\
\hline \multicolumn{3}{|l|}{ Current living arrangements } \\
\hline Alone & $81(49.7)$ & $71(43.3)$ \\
\hline With family or partner & $41(25.2)$ & $57(34.8)$ \\
\hline House share, hostel, or temporary & $41(25.2)$ & $36(22.0)$ \\
\hline \multicolumn{3}{|l|}{ Ethnicity } \\
\hline White & $131(80.4)$ & $135(82.3)$ \\
\hline Black & $18(11.0)$ & $17(10.4)$ \\
\hline Asian & $4(2.5)$ & $8(4.9)$ \\
\hline Other & $10(6.1)$ & $4(2.4)$ \\
\hline Age on leaving education (mean (SD)) & $16.2(2.1)$ & $16.0(1.6)$ \\
\hline \multicolumn{3}{|l|}{ Employment } \\
\hline Unemployed & $150(92.0)$ & $153(93.3)$ \\
\hline Employed, retired, or student & $13(8.0)$ & $11(6.7)$ \\
\hline History of psychosis (years; mean (SD)) & $12.8(9.8)$ & $11.6(8.7)$ \\
\hline \multicolumn{3}{|l|}{ Case note diagnosis } \\
\hline Schizophrenia & $134(82.2)$ & $133(81.1)$ \\
\hline Schizophreniform disorder & $3(1.8)$ & $1(0.6)$ \\
\hline Schizoaffective disorder & $14(8.6)$ & $13(7.9)$ \\
\hline Psychosis not otherwise specified & $12(7.4)$ & $17(10.4)$ \\
\hline \multicolumn{3}{|l|}{ History in pre-baseline year } \\
\hline Admitted & $32(19.6)$ & $46(28.0)$ \\
\hline Relapsed & $54(33.1)$ & $68(41.5)$ \\
\hline Drug attitude inventory compliance rating & $133(81.6)$ & $138(84.1)$ \\
\hline $\begin{array}{l}\text { Usual care provided by assertive outreach and dual diagnosis } \\
\text { service rather than by community mental health team }\end{array}$ & $13(8.0)$ & $11(6.7)$ \\
\hline History of substance use (years; mean (SD)) & $14.5(9.6)$ & $13.1(9.8)$ \\
\hline Alcohol use disorders identification test* (0-40 scale; mean (SD)) & $21.5(7.8)$ & $21.1(7.6)$ \\
\hline Drug abuse screening test† (0-20 scale; mean (SD)) & $8.2(4.2)$ & $9.4(4.4)$ \\
\hline \multicolumn{3}{|l|}{ DSM-IV diagnosis (main substance) } \\
\hline Dependence & $132(81.0)$ & $140(85.4)$ \\
\hline Abuse & $31(19.0)$ & $24(14.6)$ \\
\hline \multicolumn{3}{|l|}{ Substance types with DSM-IV diagnosis $\ddagger$} \\
\hline Alcohol only & $80(49.1)$ & $77(47.0)$ \\
\hline Drug only & $56(34.4)$ & $60(36.6)$ \\
\hline Alcohol and drug & $27(16.6)$ & $27(16.5)$ \\
\hline
\end{tabular}

Values are $\mathrm{n}(\%)$ unless otherwise specified.

*Participants with main substance alcohol; scores $>15$ reflect "high problems."

tParticipants with main substance a drug; scores between 6 and 10 reflect "moderate problems."

$\ddagger$ Meeting Diagnostic and Statistical Manual of Mental Disorders, fourth edition (DSM-IV), diagnosis of dependence on or abuse of drugs, alcohol, or both.

and one year after completion of treatment (24 months), with two additional assessment points at six and 18 months for evaluation of substance use (timeline followback). Precautions were taken to maintain the blindness of the study; for example, research and therapy staff were located in separate offices, assessment and therapy data were stored separately, appointments were managed by a third party in order to avoid appointment clashes, and patients and care coordinators were reminded before and at the start of each assessment not to give information that might "unblind" the assessor. Throughout the trial, 135 breaks in the blindness of an assessor were reported in total. However, only one assessment was completed unblinded; in all other cases a new "blind" assessor was allocated.

\section{Primary outcome}

The primary outcome for the trial was admission to hospital for a reason related to psychosis or death from any cause, versus not admitted to hospital and alive in the 12 month post-treatment period. Data were obtained from participant psychiatric case notes. Admissions made specifically for a pre-planned change of medication were not counted.

\section{Secondary outcomes: relapses and admissions}

Case notes were also used to assess frequency and duration of hospital admissions and relapses in the year before the trial and during the two year trial period. Relapse was defined as an exacerbation of psychotic symptoms that lasted longer than two weeks and required a change in patient management (medication change, increased observation by the clinical team (including hospitalisation), or both). For each participant, dates of every admission and discharge, and the start and end of each period of relapse, were recorded, as well as verbatim extractions from the notes describing changes in symptoms and management.

Before assessing participant notes, research assistants were trained to protocol then extracted data from a set of six test cases and rated admissions and relapses. Inter-rater reliability across all assessors was excellent, ${ }^{31}$ with the following mean intraclass correlation coefficients: admission (yes/no) 0.98; number of admissions 0.93 ; weeks in admission 0.82 ; relapse (yes/no) 0.87; and number of relapses 0.85. Regular supervision and data checking were provided to ensure consistency and adherence to protocol.

\section{Secondary outcomes: substance use}

The readiness to change questionnaire ${ }^{32}$ and the inventory of drug use consequences ${ }^{33}$ were used to assess motivation to change substance misuse and perceived negative consequences of misuse, respectively. Frequency and quantity of substance misuse were assessed using the timeline followback method, ${ }^{34}$ which has good reported reliability and validity in dual diagnosis populations. $^{35-37}$ The timeline followback procedure reconstructs daily substance use by detailed inquiry from an interviewer and use of a calendar with salient prompts to aid recall.

Where participants met DSM-IV abuse or dependence criteria for more than one substance, the main substance was identified as that perceived by the participant to be most problematic or, if the person did not make such a distinction, the most frequently used. Substance use was evaluated in terms of both the patient's main substance and all substances consumed by using measures of frequency (percentage days abstinent) and severity (percentage change from baseline in average amount per using day), as calculated from participants' timeline followback reports. At each assessment point patients were asked to report all substance use per day during the previous 90 days, irrespective of specific use at baseline. Alcoholic drinks were translated into standard UK units ( 1 unit=10 $\mathrm{ml}$ pure ethanol) and drugs 
Potentially eligible and approached for screening $(n=722)^{\star}$

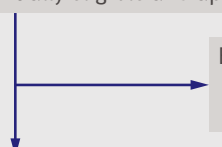
Excluded $(\mathrm{n}=151)$

Refused when asked by care coordinator $(n=85)$

Refused when asked by research assistant $(n=66)$

Screened for substance use $(n=571)$
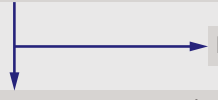

Did not meet substance use eligibility criteria $(n=244)$

Randomised $(n=327)$

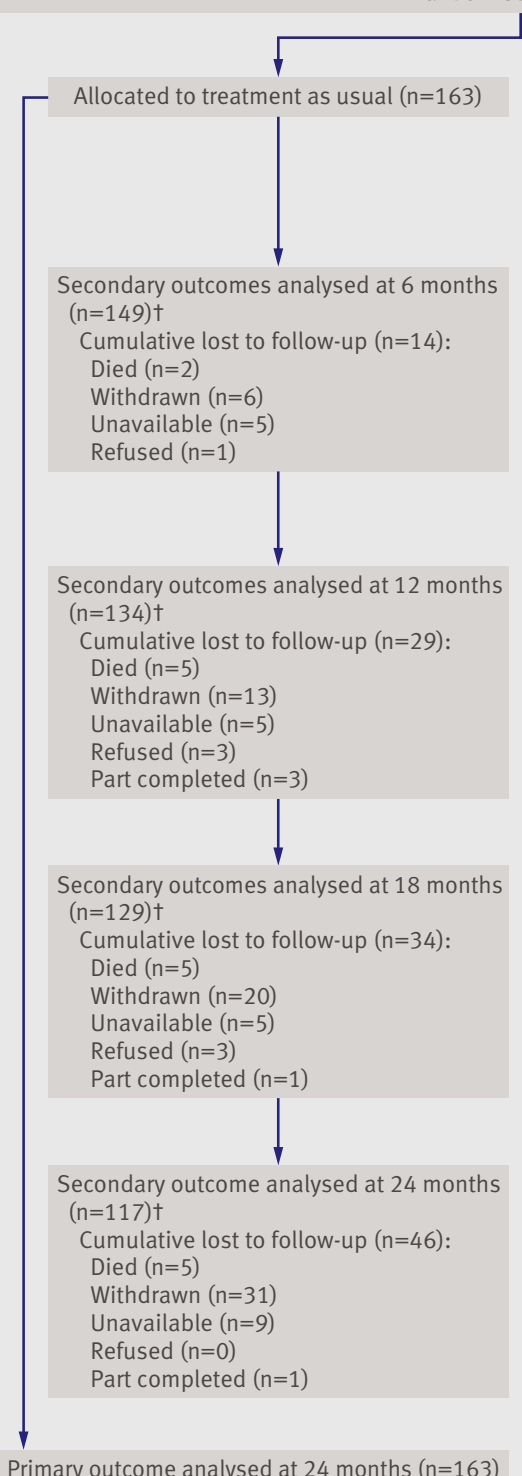

1

Allocated to therapy $(n=164)$ :

$0-2$ therapy sessions $(n=15)$

3-10 sessions $(n=25)$

$11-20$ sessions $(n=57)$

$21+$ sessions $(n=67)$

\section{$\downarrow$}

Secondary outcomes analysed at 6 months

$(n=147) \dagger$

Cumulative lost to follow-up $(n=17)$ :

Died $(n=1)$

Withdrawn $(n=6)$

Unavailable $(n=5)$

Refused $(n=3)$

Part completed $(n=1)$

Misdiagnosis $(n=1) \ddagger$

\section{Secondary outcomes anal}

Secondary outcomes analysed at 12 months

$(n=135) \dagger$

Cumulative lost to follow-up $(n=29)$ :

Died $(n=2)$

Withdrawn $(n=11)$

Unavailable $(n=4)$

Refused $(n=4)$

Part completed $(n=7)$

Misdiagnosis $(n=1) \neq$

\section{Secondary outcomes ana}

Secondary outcomes analysed at 18 months

$(n=131) \dagger$

Cumulative lost to follow-up $(n=33)$ :

Died $(n=2)$

Withdrawn $(n=17)$

Unavailable $(n=4)$

Refused $(n=6)$

Part completed $(n=3)$

Misdiagnosis $(n=1) \ddagger$

\section{Secondary outcome analysed at 24 months \\ $(n=129) \dagger$}

Cumulative lost to follow-up $(n=35)$ :

Died $(n=2)$

Withdrawn $(n=25)$

Unavailable $(n=7)$

Refused $(n=0)$

Part completed $(n=0)$

Misdiagnosis $(n=1) \ddagger$

Primary outcome analysed at 24 months $(n=163)$ Misdiagnosis $(n=1) \neq$

Fig 1 | CONSORT diagram showing patient flow through the trial. *Identified by care coordinator and psychiatric diagnosis confirmed from case notes. †Positive and negative syndrome scale and timeline followback assessments completed. $\ddagger$ One patient with a clinical diagnosis of schizophrenia was randomly allocated to psychological therapy but subsequently received a diagnosis of bipolar affective disorder and withdrew from the trial before receiving therapy

were recorded by weight and cost or by number of tablets and cost, as appropriate.

To provide collateral checks on participants' self reports, care coordinators completed abbreviated timeline followback assessments (reports of patients'

substance use per week during the previous 90 days) and the alcohol use scale and drug use scale of the clinician rating scales ${ }^{38}$ at baseline and at $6,12,18$, and 24 months. Additionally, we aimed to ask $25 \%$ of consenting participants to give hair samples that were later analysed by a specialist hair analysis company (TrichoTech Ltd, Abingdon, Oxfordshire) to detect the presence of illicit drug use.

\section{Secondary outcomes: symptoms and functioning}

The total score and scores on the positive, negative, and general subscales of the positive and negative syndrome scale were used to assess symptoms of psychosis. ${ }^{39}$ Participants' functioning was assessed using the total score and scores on the symptoms and functioning subscales of the global assessment of functioning. ${ }^{40}$ Occurrence (yes/no) of an episode of deliberate self harm in the previous 12 months was obtained via self report by using a brief structured interview.

All trained assessors used the positive and negative syndrome scale to rate 10 "gold standard" video recorded interviews before starting trial assessments. Mean intraclass correlation coefficients across all assessors indicated excellent inter-rater reliability: positive subscale 0.89 ; negative subscale 0.85 ; general subscale 0.88 ; and total score 0.86 . Ratings were checked throughout the trial by using a random sample of 24 recorded interviews with trial participants. Intraclass correlation coefficients ranged from excellent to good agreement: for the positive and negative syndrome scale, positive subscale 0.76 ; negative subscale 0.72 ; general subscale 0.71 ; total 0.70 ; and for the global assessment of functioning 0.70 .

\section{Sample size and power}

On the basis of our earlier study, ${ }^{10}$ we estimated that $60 \%$ of the control group would either die or be admitted to hospital during the follow-up period, and we allowed for $10 \%$ attrition owing to inadequate or unavailable case notes. A sample size of 180 patients in each group would have about $95 \%$ power to detect a difference between the two groups with a significance level of 0.05 , assuming that the rate of admission or death would be reduced from $60 \%$ to $40 \%$ in the treatment arm. Thus we aimed to recruit 400 patients.

We revised this sample size to 320 in February 2006 because recruitment was slower than anticipated. This number of patients would provide primary outcome data on 140 participants per group, with about $90 \%$ power to detect a reduction in the rate of admission or death from $60 \%$ to $40 \%$. We estimated that we would also have secondary outcome data on 130 participants per arm and thus have $80 \%$ power to detect an effect size of 0.35 with a two sided significance level of 0.05 .

\section{Statistical analysis}

Data were analysed according to the intention to treat principle. All analyses to estimate treatment effects were variations on an analysis of covariance that allowed for location (NHS trust) and main substance used. The 
Table 2 | Substance use at baseline

\begin{tabular}{lcccccc} 
& \multicolumn{2}{c}{ Control $(\mathrm{n}=163)$} & & \multicolumn{2}{c}{ Therapy $(\mathrm{n}=164)$} \\
\cline { 2 - 3 } \cline { 6 - 7 } & $\begin{array}{c}\text { Main substance } \\
(\mathrm{n}(\%))\end{array}$ & $\begin{array}{c}\text { Any use }(\mathrm{n} \\
(\%)\end{array}$ & & $\begin{array}{c}\text { Main substance } \\
(\mathrm{n}(\%))\end{array}$ & $\begin{array}{c}\text { Any use } \\
(\mathrm{n}(\%))\end{array}$ \\
\hline Alcohol* & $93(57.1)$ & $107(65.6)$ & & $94(57.3)$ & $104(63.4)$ \\
\hline Cannabis & $42(25.8)$ & $82(50.3)$ & & $40(24.4)$ & $78(47.6)$ \\
\hline Cocaine & $5(3.1)$ & $15(9.2)$ & & $1(0.6)$ & $12(7.3)$ \\
\hline Ecstasy & $0(0.0)$ & $12(7.4)$ & & $1(0.6)$ & $5(3.0)$ \\
\hline Heroin & $6(3.7)$ & $15(9.2)$ & & $6(3.7)$ & $17(10.4)$ \\
\hline Amphetamines & $8(4.9)$ & $17(10.4)$ & & $11(6.7)$ & $27(16.5)$ \\
\hline Crack & $8(4.9)$ & $13(8.0)$ & & $9(5.5)$ & $22(13.4)$ \\
\hline Other & $1(0.6)$ & $14(8.6)$ & & $2(1.2)$ & $16(9.8)$ \\
\hline Polysubstance uset & - & $72(44.2)$ & & - & $70(42.7)$ \\
\hline
\end{tabular}

*Alcohol use meeting Diagnostic and Statistical Manual of Mental Disorders, fourth edition, dependence or abuse criteria.

†Two or more substances, including use of any illicit drug, alcohol above safe limits, or both.

exact form of the analysis depended on whether the data were binary, ordinal, or quantitative. For secondary outcomes, the baseline value for the relevant outcome measure was covaried where appropriate. Gender, service type, and living circumstances were also included as baseline covariates because they were found predictive of attrition in a preliminary analysis of missing secondary outcome data. Implicit in these analyses was the assumption that data were missing completely at random after conditioning on all of the baseline covariates. Where quantitative outcomes were positively skewed, standard errors for parameters, and their confidence intervals and $P$ values, were obtained through the use of robust "sandwich" estimates. $^{41}$

With the exception of the timeline followback, secondary outcomes were analysed separately for the two assessment points (12 and 24 months). To reduce the number of analyses and the likelihood of type 1 errors, timeline followback variables were evaluated across the four time points $(6,12,18$, and 24 months) by using repeated measures analysis, with models estimating treatment effects common to all time points. Quantitative outcomes (frequency of substance use) were analysed using a random effects model. In order to deal with their highly skewed distributions, timeline followback variables assessing change from baseline in average daily amount of substance use were recoded into five point ordinal severity scales, with codes 1 and 2 corresponding to deterioration and 3-5 to improvement $(1=$ more than $20 \%$ increase, $2=$ up to $20 \%$ increase, $3=39 \%$ to $0 \%$ reduction, $4=40 \%$ to $79 \%$ reduction, and $5=80 \%$ to $100 \%$ reduction). Treatment effects for these ordinal outcome scales were estimated via a marginal ordinal regression model that allowed for the covariates and for time as a within person effect, with the participant as the clustering variable. Again, robust "sandwich" estimators were used for the evaluation of these treatment effects.

\section{RESULTS}

\section{Participants}

A total of 722 patients were referred to the trial: 151 declined to be screened for eligibility; 244 did not meet substance use criteria at screening; and 327 underwent baseline assessment and were randomised. Data on the primary outcome were collected for 326 (99.7\%) participants. Key secondary outcomes (positive and negative syndrome scale and timeline followback) were available for $269(82.2 \%)$ participants at 12 months and $246(75.2 \%)$ participants at 24 months. Participant flow through the trial is shown in figure 1 .

Table 1 presents demographic information and psychiatric and substance use history for patients allocated to each trial arm. Participants had a mean age of late $30 \mathrm{~s}$, were predominantly male, and tended to be living on their own without a family or partner. They had long self reported histories of both psychosis and substance use. Baseline case note diagnoses are given in table 1. All psychiatric diagnoses were re-assessed by chart review at the end of the trial and $323(98.8 \%)$ participants fulfilled DSM-IV criteria for non-affective psychosis, whereas four $(1.2 \%)$ met criteria for affective psychosis.

Substance use at baseline is shown in table 2. Participants reported alcohol and drug use on most days (table 3) and their responses to the readiness to change questionnaire (table 4) indicated that few people entered the study at an action stage for reducing their main substance. Table 5 shows symptom and functioning profiles at baseline. Mean general functioning was low, with $96 \%$ of participants in the range from serious impairments to inability to function in almost all areas (global assessment of functioning scores 50 to 21).

\section{Validity of patient timeline followback}

Comparison of patient self reports with hair samples, care coordinator reports (abbreviated timeline followback and clinician rating scales), and baseline patient alcohol use disorders identification test or drug misuse screening test indicated adequate concurrent validity.

At baseline, 241 participants (74\%) gave consent for a hair sample to be taken, 60 (25\%) of whom were randomly selected. The refusal rate during assessments was high $(42 \%)$, and a third (34\%) of patients had insufficient head hair, thus after March 2007 we approached all patients who gave initial consent. In total, 61 participants $(19 \%)$ provided hair samples for at least one time point.

Averaged across eight substances (cannabis, amphetamine, heroin, cocaine, crack, ecstasy, methadone, and benzodiazepines), the agreement between substances identified in hair samples and substances reported by the participant on the timeline followback was $\kappa=0.67$, the agreement for cannabis being $\kappa=0.55$. The mean agreement between patient self reports and care coordinator reports for seven substances (alcohol, cannabis, amphetamine, heroin, cocaine, crack, and ecstasy; methadone and benzodiazepines were excluded owing to insufficient reports), averaged across the five assessments was $\kappa=0.62$ (alcohol $\kappa=0.62$; cannabis $\kappa=0.70)$.

There were significant $(\mathrm{P}<0.01)$ associations between patient and care coordinator timeline followback reports, with intraclass correlation coefficients as follows: percentage of days abstinent from main 
Table 3 | Substance use: frequency of substance use (timeline followback) and inventory of drug use consequences

\begin{tabular}{|c|c|c|c|c|}
\hline & \multicolumn{2}{|c|}{ Control } & \multicolumn{2}{|c|}{ Therapy } \\
\hline & Total $\mathrm{n}$ & Mean (SD) & Total $n$ & Mean (SD) \\
\hline \multicolumn{5}{|c|}{ Proportion of days abstinent from main substance (\%) } \\
\hline Baseline & 163 & $27.11(27.32)$ & 163 & $28.68(27.27)$ \\
\hline 6 months & 148 & $39.60(38.31)$ & 147 & $38.90(36.40)$ \\
\hline 12 months & 137 & $41.49(37.29)$ & 138 & $48.30(37.82)$ \\
\hline 18 months & 128 & $49.20(38.68)$ & 130 & $47.99(39.45)$ \\
\hline 24 months & 117 & $48.77(39.69)$ & 129 & $51.29(39.80)$ \\
\hline \multicolumn{5}{|c|}{ Proportion of days abstinent from all substances (\%) } \\
\hline Baseline & 160 & $22.72(24.89)$ & 163 & $25.81(26.03)$ \\
\hline 6 months & 148 & $30.06(35.18)$ & 147 & $34.27(34.01)$ \\
\hline 12 months & 136 & $34.51(34.18)$ & 137 & $40.24(36.18)$ \\
\hline 18 months & 127 & 38.47 (34.94) & 129 & $38.17(37.23)$ \\
\hline 24 months & 117 & $37.18(36.89)$ & 130 & $44.25(38.36)$ \\
\hline \multicolumn{5}{|c|}{ Inventory of drug use consequences (0-45 scale) } \\
\hline Baseline & 160 & $15.60(11.28)$ & 159 & $16.06(10.24)$ \\
\hline 12 months & 128 & $12.49(11.08)$ & 129 & $12.19(11.23)$ \\
\hline 24 months & 117 & $11.50(11.93)$ & 124 & $11.23(11.23)$ \\
\hline
\end{tabular}

substance 0.67 ; percentage change in average daily amount of main substance 0.39 ; units of alcohol 0.63 ; and weight of cannabis 0.49 . There were also significant associations between care coordinator reports on the alcohol use scale of the clinician rating scales and percentage of days abstinent from main substance (Spearman's $\rho=-0.40)$ and units of alcohol $(\rho=0.50)$. Care coordinator reports on the drug use scale were significantly associated with the weight of cannabis consumed $(\rho=0.48)$ but not with days abstinent from drug use $(\rho=-0.17)$. Baseline self reported severity measures (alcohol use disorders identification test or drug misuse screening test) showed good association with amounts of alcohol consumed $(\rho=0.54)$ and cannabis use $(\rho=0.39)$, but had weak and non-significant associations with days abstinent (cannabis $\rho=-0.11$; alcohol $\rho=-0.13)$.

\section{Treatment delivered and treatment fidelity}

The mean number of sessions delivered to patients who were allocated to psychological therapy was 16.7 (SD 8.3). The number of items rated as compliant on the treatment fidelity scale ranged from $13 / 16(81 \%)$ to $16 / 16(100 \%)$ across the 40 sessions audiotaped sessions rated.

\section{Outcomes}

\section{Primary outcome}

During the total 24 month study period, there were two $(1.2 \%)$ deaths among the 163 individuals in the therapy group analysed and five $(3.1 \%)$ deaths in the 163 patients in the control group. A higher proportion of patients in the therapy group than in the control group were admitted during follow-up (including those in hospital at the point of follow-up; $22.1 \%(36 / 163)$ and $17.2 \%$ (28/163), respectively). Thus $23.3 \%(38 / 163)$ of the therapy group and $20.2 \%(33 / 163)$ of the control group reached the primary outcome criteria. This difference was non-significant (adjusted odds ratio 1.16, $95 \%$ confidence interval 0.68 to $1.99 ; \mathrm{P}=0.579$ ), with the adjusted model predicting the primary outcome for $22.2 \%$ of the therapy group and $19.7 \%$ of the control group.

\section{Secondary outcomes: relapse and admissions}

During the 24 month trial period, 39.1\% (63/161) of the therapy group and $37.9 \%(61 / 161)$ of the control group experienced at least one relapse in psychotic symptoms, a non-significant difference (adjusted OR $1.05,95 \%$ CI 0.67 to $1.66 ; \mathrm{P}=0.833)$. Descriptive statistics for the number and duration of relapses and admissions during the intervention and follow-up year are provided in table 5 . There were no significant differences between the therapy group and control group on any of these outcomes.

\section{Secondary outcomes: substance use}

For percentage days abstinent from substance use (table 3), there was no difference between the therapy group and the control group for either main substance (adjusted coefficient estimated using random effects $1.28,95 \% \mathrm{CI}-5.88$ to $8.45 ; \mathrm{P}=0.725)$ or all substances (4.18, 95\% CI -2.63 to $11.00 ; \mathrm{P}=0.229)$. However, the integrated therapy was found to have a statistically significant effect on the amount of substance used per substance using day (table 6, fig 2) in terms of both main substance (adjusted OR estimated using ordinal regression $1.50,95 \%$ CI 1.08 to $2.09 ; \mathrm{P}=0.016)$ and all substances $(1.48,95 \%$ CI 1.07 to $2.05 ; \mathrm{P}=0.017)$. Thus for the therapy group, the odds of being in one of the more abstinent groups versus one of the less abstinent groups are 1.50 times higher than for the control group for main substance (1.48 higher for all substances), given the other variables in the model are held constant.

Table 6 shows that the proportion of participants who had reduced their average daily intake of the main substance since baseline was $20 \%$ greater $(18 \%$ for all substances) in the therapy group than in the control group (averaged across follow-up assessments).

\begin{tabular}{|c|c|c|c|c|}
\hline & \multicolumn{2}{|c|}{ Control } & \multicolumn{2}{|c|}{ Therapy } \\
\hline & Total $n$ & n (\%) & Total $n$ & n (\%) \\
\hline \multicolumn{5}{|l|}{ Baseline } \\
\hline Pre-contemplative & 162 & $40(24.7)$ & 163 & $43(26.4)$ \\
\hline Contemplative & 162 & $71(43.8)$ & 163 & $80(49.1)$ \\
\hline Action & 162 & $51(31.5)$ & 163 & $40(24.5)$ \\
\hline \multicolumn{5}{|l|}{12 months } \\
\hline Pre-contemplative & 134 & $37(27.6)$ & 139 & $23(16.5)$ \\
\hline Contemplative & 134 & $47(35.1)$ & 139 & 47 (33.8) \\
\hline Action & 134 & $50(37.3)$ & 139 & 69 (49.6) \\
\hline \multicolumn{5}{|l|}{24 months } \\
\hline Pre-contemplative & 118 & $27(22.9)$ & 126 & $30(23.8)$ \\
\hline Contemplative & 118 & $40(33.9)$ & 126 & $51(40.5)$ \\
\hline Action & 118 & $51(43.2)$ & 126 & $45(35.7)$ \\
\hline
\end{tabular}


Table 5 | Mean (SD) scores and robust treatment effect estimates: positive and negative syndrome scale, global assessment of functioning, and number and duration of admissions and relapses

\begin{tabular}{|c|c|c|c|c|c|c|c|}
\hline & \multicolumn{2}{|c|}{ Control } & \multicolumn{2}{|c|}{ Therapy } & \multicolumn{3}{|c|}{ Robust treatment effect estimates } \\
\hline & $\mathrm{n}$ & Mean (SD) & $\mathrm{n}$ & Mean (SD) & Coefficient $(95 \% \mathrm{Cl})$ & SE & P value \\
\hline \multicolumn{8}{|c|}{ Positive and negative syndrome scale* } \\
\hline Baseline & & & & & & - & - \\
\hline Positive & 163 & $16.11(5.50)$ & 164 & $15.92(5.16)$ & - & - & - \\
\hline Negative & 163 & $13.44(4.13)$ & 164 & $14.49(4.77)$ & - & - & - \\
\hline General & 163 & $31.63(7.53)$ & 164 & $33.24(8.01)$ & - & - & - \\
\hline Total & 163 & $61.17(13.25)$ & 164 & $63.65(14.26)$ & - & - & - \\
\hline \multicolumn{8}{|l|}{12 months } \\
\hline Positive & 137 & $14.59(5.35)$ & 137 & $14.62(4.85)$ & $-0.01(-1.00$ to 0.99$)$ & 0.51 & 0.93 \\
\hline Negative & 137 & $12.97(4.08)$ & 137 & $13.36(4.65)$ & $-0.31(-1.20$ to 0.58$)$ & 0.45 & 0.49 \\
\hline General & 137 & $27.74(6.94)$ & 137 & $29.85(7.52)$ & $0.85(-0.60$ to 2.30$)$ & 0.74 & 0.25 \\
\hline Total & 137 & $55.30(12.98)$ & 137 & $57.82(14.10)$ & $0.27(-2.31$ to 2.86$)$ & 1.31 & 0.84 \\
\hline \multicolumn{8}{|l|}{24 months } \\
\hline Positive & 118 & $13.55(5.22)$ & 129 & $14.07(5.38)$ & $0.48(-0.59$ to 1.55$)$ & 0.54 & 0.37 \\
\hline Negative & 118 & $12.46(3.78)$ & 129 & $12.62(4.24)$ & $-0.29(-1.19$ to 0.61$)$ & 0.46 & 0.53 \\
\hline General & 118 & $25.84(6.44)$ & 129 & $27.87(7.80)$ & $1.06(-0.49$ to 2.60$)$ & 0.78 & 0.18 \\
\hline Total & 118 & $51.85(11.57)$ & 129 & $54.56(14.70)$ & $1.02(-1.76$ to 3.80$)$ & 1.41 & 0.47 \\
\hline \multicolumn{8}{|c|}{ Global assessment of functioning $\dagger$} \\
\hline \multicolumn{8}{|l|}{ Baseline } \\
\hline Symptoms & 160 & $40.22(15.66)$ & 163 & $39.32(14.58)$ & - & - & - \\
\hline Disability & 160 & $40.57(9.58)$ & 163 & $38.74(7.19)$ & - & - & - \\
\hline Total & 160 & $34.99(10.10)$ & 163 & 33.57 (7.59) & - & - & - \\
\hline \multicolumn{8}{|l|}{12 months } \\
\hline Symptoms & 134 & $41.87(15.60)$ & 135 & $41.06(15.63)$ & $-0.69(-2.31$ to 2.86$)$ & 1.75 & 0.84 \\
\hline Disability & 134 & $40.28(8.56)$ & 135 & $39.25(8.96)$ & $-0.13(-1.98$ to 1.73$)$ & 1.67 & 0.89 \\
\hline Total & 134 & $35.60(9.36)$ & 135 & $34.96(9.46)$ & $-0.11(-2.16$ to 1.95$)$ & 1.04 & 0.92 \\
\hline \multicolumn{8}{|l|}{24 months } \\
\hline Symptoms & 115 & $44.46(16.69)$ & 119 & $42.92(17.14)$ & $-1.43(-5.48$ to 2.62$)$ & 2.06 & 0.49 \\
\hline Disability & 115 & $40.12(11.51)$ & 119 & $39.70(9.61)$ & $0.17(-2.44$ to 2.78$)$ & 1.32 & 0.90 \\
\hline Total & 115 & $36.18(10.27)$ & 119 & $35.97(10.93)$ & $0.28(-2.19$ to 2.76$)$ & 1.26 & 0.82 \\
\hline \multicolumn{8}{|c|}{ Admissions in past 12 months } \\
\hline \multicolumn{8}{|c|}{ Number of admissions } \\
\hline Baseline & 162 & $0.28(0.63)$ & 161 & $0.41(0.82)$ & - & - & - \\
\hline 12 months & 162 & $0.22(0.63)$ & 163 & $0.22(0.58)$ & $-0.01(-0.14$ to 0.12$)$ & 0.07 & 0.92 \\
\hline 24 months & 159 & $0.19(0.49)$ & 162 & $0.27(0.65)$ & $0.08(-0.05$ to 0.20$)$ & 0.06 & 0.22 \\
\hline \multicolumn{8}{|l|}{ Days admitted } \\
\hline Baseline & 162 & $10.86(32.43)$ & 161 & $14.63(37.30)$ & - & - & - \\
\hline 12 months & 162 & $10.35(38.31)$ & 163 & $12.64(46.46)$ & $2.32(-7.16$ to 11.80$)$ & 4.82 & 0.63 \\
\hline 24 months & 159 & $14.01(52.21)$ & 162 & $15.74(44.59)$ & $1.53(-9.48$ to 12.54$)$ & 5.60 & 0.78 \\
\hline \multicolumn{8}{|c|}{ Relapses in past 12 months } \\
\hline \multicolumn{8}{|c|}{ Number of relapses } \\
\hline Baseline & 161 & $0.40(0.60)$ & 161 & $0.53(0.71)$ & - & - & - \\
\hline 12 months & 161 & $0.27(0.54)$ & 161 & $0.30(0.58)$ & $0.02(-0.10$ to 0.15$)$ & 0.06 & 0.71 \\
\hline 24 months & 159 & $0.23(0.45)$ & 161 & $0.27(0.55)$ & $0.04(-0.07$ to 0.15$)$ & 0.06 & 0.45 \\
\hline \multicolumn{8}{|c|}{ Days in relapse } \\
\hline Baseline & 161 & $48.96(91.70)$ & 161 & $62.04(97.45)$ & - & - & - \\
\hline 12 months & 161 & $37.08(76.84)$ & 161 & $53.98(95.56)$ & $15.90(-2.89$ to 34.69$)$ & 9.55 & 0.10 \\
\hline 24 months & 159 & $40.23(87.32)$ & 161 & $40.48(81.55)$ & $-1.86(-20.58$ to 16.85$)$ & 9.51 & 0.85 \\
\hline
\end{tabular}

Compared with controls, patients allocated to the integrated therapy significantly increased their motivation to reduce substances at 12 months (adjusted OR 2.05, $95 \%$ CI 1.26 to $3.31 ; \mathrm{P}=0.004$ ), although this significant effect was not maintained at 24 months $(0.78,95 \% \mathrm{CI}$ 0.48 to $1.28 ; \mathrm{P}=0.320$; table 4 ). For perceived consequences of substance use, there were no differences between the therapy group and the control group at 


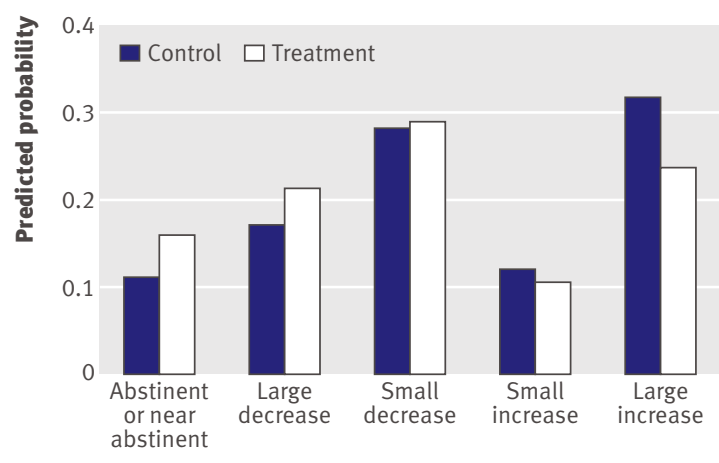

Fig 2 | Predicted probabilities of being in each of the five change in substance use categories (change from baseline in average daily amount of main substance) for therapy and control groups, based on a repeated measures marginal ordinal regression model that allowed for baseline covariates

12 months (adjusted coefficient $-0.31,95 \% \mathrm{CI}-2.60$ to $1.98 ; \mathrm{P}=0.787)$ or at 24 months $(-0.65,95 \% \mathrm{CI}-3.21$ to $1.92 ; \mathrm{P}=0.620$; table 3$)$.

\section{Secondary outcomes: symptoms and functioning}

There were no statistically significant differences between the two groups in terms of symptoms (positive and negative syndrome scale) or functioning (global assessment of functioning; table 5). At 12 month assessment, $14.4 \%(19 / 132)$ of participants in the therapy group and $11.9 \%(16 / 135)$ in the control group reported having deliberately self harmed during the previous 12 month period. At 24 months, 9.5\% $(12 / 126)$ of the therapy group and $6.8 \%(8 / 117)$ of the control group reported self harm. The difference between groups was not significant at either time point (adjusted odds ratio at 12 months: $1.38,95 \% \mathrm{CI}$ 0.65 to $2.96, \mathrm{P}=0.402 ; 24$ months: $1.48,95 \%$ CI 0.56 to $3.91 ; \mathrm{P}=0.433)$.

\section{Safety of treatment and adverse events}

There were seven participant deaths during the course of the trial: two in the therapy group and five in the control group. The causes were recorded as suicide, non-dependent use of drugs, stroke, cancer, genetic disorder, heart attack, and multiple physical conditions. Four participants were admitted to a secure unit during the trial, three of whom were receiving the intervention and one who was receiving treatment as usual. Our independent data monitoring committee was informed of all the above events and considered them unrelated to the trial treatments.

\section{Exploratory analyses of alcohol subgroup}

To explore whether the lack of effect of the therapy was consistent for all substance use groups we examined the largest subgroup -individuals who met only alcohol dependence or abuse criteria at baseline-and compared it to the remaining participants. There was a statistically significant treatment by subgroup interaction on the percentage of days abstinent from the main substance (repeated measures analysis): the difference in means between the therapy group and the control group for those individuals using alcohol only $(\mathrm{n}=142)$ was $10.72 \%$ (95\% CI 1.05 to $20.38 ; \mathrm{P}=0.030)$ and that for the remaining individuals $(\mathrm{n}=158)$ was $-7.42 \%$ (95\% CI -17.55 to $2.72 ; \mathrm{P}=0.152)$, the difference between the treatment effects (the interaction) being $18.13 \%$ (95\% CI 4.24 to 32.03 ; $\mathrm{P}=0.011)$. No treatment by subgroup interactions were found either on the primary outcome or on any other secondary outcome.

\section{DISCUSSION}

Principal findings

This study shows that, when compared with treatment as usual, integrated motivational interviewing and cognitive behavioural therapy for people with psychosis and substance misuse does not improve outcome in terms of deaths and hospitalisations, nor does it result in improvements in other key clinical outcomes including relapses, psychotic symptoms, functioning, and self harm.

The integrated therapy did result in an increased readiness to make changes in substance use by the end of treatment, although this improved motivation was reduced and no longer significant one year after completion. However, this benefit was not sufficient to influence clinical outcomes. The loss of improvement in readiness to change scores by two year follow-up would suggest that motivation to reduce substance use waned in the year after therapy terminated. Even a treatment period of a year may have been too short for participating patients who had long histories of heavy drug and alcohol misuse (often characterised by polysubstance use), complex and longstanding mental health problems, and low levels of social functioning and support.

Patients in the therapy group were also more likely to have reduced the amount of drink and drugs they consumed when compared with people in the control group. This better outcome was maintained over the two year study and was evident for both patients' main substance (as reported at start of study) and for all other substances used over the course of the study. At the same time, there was no effect of therapy on the frequency of substance misuse.

For individuals with psychosis who reported only alcohol abuse or dependence, the psychological therapy had significant effects in terms of an increase in days abstinent, which endured over the two year follow-up. The exploratory analyses need to be viewed with caution because they were unplanned and the study was not designed to test differences in treatment effects for subgroups. However, this differential effect of the intervention according to substance type would be consistent with outcome research in substance users without mental health problems. Multiple psychosocial treatments have been found to be efficacious for alcohol problems in groups who do not have a dual diagnosis, ${ }^{42}$ and brief motivational interventions have been found to reduce alcohol consumption even in groups not seeking treatment. ${ }^{43}$ On the other hand, response rates for treatment for cannabis misuse, 
Table 6 |Ranked change scores of substance use at the four follow-up assessments (change from baseline in average amount per substance using day)

\begin{tabular}{|c|c|c|c|c|c|c|c|c|c|c|c|c|c|}
\hline & \multicolumn{6}{|c|}{ Control } & \multicolumn{6}{|c|}{ Therapy } & \multirow{2}{*}{$\begin{array}{l}\text { Increase in } \\
\text { probability of } \\
\text { improvement in } \\
\text { therapy group* }\end{array}$} \\
\hline & $\mathrm{n}$ & $\begin{array}{l}\text { Abstinent } \\
\text { or near } \\
\text { abstinent }\end{array}$ & $\begin{array}{c}\text { Large } \\
\text { decrease }\end{array}$ & $\begin{array}{c}\text { Small } \\
\text { decrease }\end{array}$ & $\begin{array}{c}\text { Small } \\
\text { increase }\end{array}$ & $\begin{array}{c}\text { Large } \\
\text { increase }\end{array}$ & $\mathrm{n}$ & $\begin{array}{c}\text { Abstinent or } \\
\text { near abstinent }\end{array}$ & $\begin{array}{c}\text { Large } \\
\text { decrease }\end{array}$ & $\begin{array}{c}\text { Small } \\
\text { decrease }\end{array}$ & $\begin{array}{c}\text { Small } \\
\text { increase }\end{array}$ & $\begin{array}{c}\text { Large } \\
\text { increase }\end{array}$ & \\
\hline \multicolumn{14}{|c|}{ Main substance } \\
\hline 6 months & 143 & $12(8.4)$ & $24(16.8)$ & $42(29.4)$ & $16(11.2)$ & $49(34.3)$ & 142 & $13(9.2)$ & $26(18.3)$ & $49(34.5)$ & $21(14.8)$ & $33(23.2)$ & $14 \%$ \\
\hline 12 months & 132 & $13(9.8)$ & $23(17.4)$ & $32(24.2)$ & $19(14.4)$ & $45(34.1)$ & 134 & $20(14.9)$ & $31(23.1)$ & $38(28.4)$ & $13(9.7)$ & $32(23.9)$ & $29 \%$ \\
\hline 18 months & 125 & $22(17.6)$ & $19(15.2)$ & $30(24.0)$ & $11(8.8)$ & $43(34.4)$ & 125 & $26(20.8)$ & $28(22.4)$ & $34(27.2)$ & $6(4.8)$ & $31(24.8)$ & $24 \%$ \\
\hline 24 months & 113 & $20(17.7)$ & $20(17.7)$ & $23(20.4)$ & $12(10.6)$ & 38 (33.6) & 125 & $27(21.6)$ & $20(16.0)$ & $32(25.6)$ & $16(12.8)$ & $30(24.0)$ & $13 \%$ \\
\hline Average & & & & & & & & & & & & & $20 \%$ \\
\hline \multicolumn{14}{|c|}{ All substances } \\
\hline 6 months & 148 & $8(5.4)$ & $21(14.2)$ & $43(29.1)$ & $21(14.2)$ & $55(37.2)$ & 143 & $8(5.6)$ & $21(14.7)$ & $47(32.9)$ & $27(18.9)$ & $40(28.0)$ & $9 \%$ \\
\hline 12 months & 136 & $9(6.6)$ & $19(14.0)$ & $34(25.0)$ & $23(16.9)$ & $51(37.5)$ & 137 & $15(10.9)$ & $30(21.9)$ & $36(26.3)$ & $20(14.6)$ & $36(26.3)$ & $30 \%$ \\
\hline 18 months & 128 & $16(12.5)$ & $20(15.6)$ & $31(24.2)$ & $14(10.9)$ & $47(36.7)$ & 127 & $18(14.2)$ & $25(19.7)$ & $39(30.7)$ & $9(7.1)$ & $36(28.3)$ & $23 \%$ \\
\hline 24 months & 115 & $11(9.6)$ & $22(19.1)$ & $26(22.6)$ & $9(7.8)$ & $47(40.9)$ & 127 & $17(13.4)$ & $21(16.5)$ & $33(26.0)$ & $20(15.7)$ & $36(28.3)$ & $9 \%$ \\
\hline Average & & & & & & & & & & & & & $18 \%$ \\
\hline
\end{tabular}

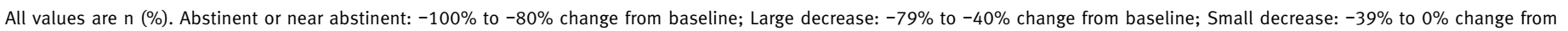
baseline; Small increase: $+1 \%$ to $+20 \%$ change from baseline; Large increase: more than $20 \%$ change from baseline.

*Percentage increase in the proportion of participants who reduced substance use ("abstinent or near abstinent," "large decrease," and "small decrease" categories) in therapy group compared with controls.

even for "motivated self referred treatment samples," have not been impressive. ${ }^{16}$ Additionally, there is consistent evidence that outcomes for polysubstance users (almost half the reported sample) are poorer. ${ }^{15}$

\section{Comparison with other studies}

A Cochrane review identified three studies that compared cognitive behavioural therapy and motivational interviewing with standard care in people with psychosis and substance misuse. ${ }^{6}$ Edwards and colleagues found no effect of intervention in a sample of patients who had experienced a recent episode of psychosis and who also used cannabis. ${ }^{44}$ Baker et al found no effect of integrated motivational interviewing and cognitive behavioural therapy on substance misuse or symptoms but a significant improvement in functioning, as assessed on the global assessment of functioning. ${ }^{45}$

Our previous study demonstrated significant benefits of cognitive behavioural therapy and motivational interviewing in terms of negative symptoms, functioning, and relapse rate at 12 month follow-up. ${ }^{10}{ }^{19}$ One factor that might explain these superior outcomes relative to the study reported here is that relapse rates in the control group in the earlier study were much higher $(67 \%$ v 38\% in the present study). Similarly, the frequency of substance use in the control group showed relatively little change from baseline in the earlier study, but there were large decreases in the control group in the current study. These better outcomes with standard care in the study reported here might reflect the widespread policy driven improvements in care for dual diagnosis patients that have occurred in the UK since 2001 . $^{7}$

\section{Strengths and limitations of study}

This is the largest randomised controlled trial to evaluate an individual level treatment for psychosis and substance misuse. We had high rates of follow-up and low refusal and dropout rates. These rates compare very favourably with dropout rates from other treatment programmes for psychosis and substance misuse, which report in excess of $50 \%$ of patients failing to engage. ${ }^{46}$ The large sample was drawn from both urban and rural populations, and the sample characteristics seem representative of patients with substance misuse and psychosis presenting to mental health services, ${ }^{24}$ who often have longstanding substance use, with frequent misuse at moderate or severe levels, in the context of low levels functioning and significant psychopathology.

Although we did not assess specific components of standard care for each participant, we attempted to reduce variation by including treatment locality as a minimisation variable in the randomisation algorithm and by providing guidelines on patient management. The majority of those allocated to treatment participated in a substantial number of therapy sessions, and therapists were well trained and supervised so we achieved good treatment fidelity. The self reports of patients regarding substance misuse were validated by assessments from other sources, and we attained good reliability on all observer rated outcomes. We did not control for the additional therapist contact associated with study participation because we sought only to assess the effectiveness of the psychological therapy relative to treatment as usual, and not to examine specific treatment effects.

For all the above reasons, we can have confidence that the trial results give a reliable indication of the outcomes from delivering integrated motivational interviewing and cognitive behavioural therapy by trained therapists to people with a diagnosis of psychosis and moderate to heavy use of alcohol, illicit drugs, or both.

\section{Conclusions and further research}

We conclude that integrated motivational interviewing and cognitive behavioural therapy for people with a 


\section{WHAT IS ALREADY KNOWN ON THIS TOPIC}

Alcohol and drug misuse in people with psychosis is common, and this comorbidity is associated with many illness complications

There is no compelling evidence to support any one psychosocial treatment for this patient group

Limited evidence indicates that integrated motivational interviewing and cognitive behavioural therapy might be helpful

Studies of integrated therapy in patients with psychosis have had recruitment and retention problems

\section{WHAT THIS STUDY ADDS}

Integrated motivational interviewing and cognitive behavioural therapy delivered over one year by trained therapists did not produce improvement in clinical outcomes for people with psychosis and substance misuse

The therapy group had improved outcomes in terms of the amount of substances consumed that were sustained over 24 months

Integrated therapy was associated with good engagement with and retention in treatment

Integrated therapy might have more effect on people who misuse alcohol than on those who misuse drugs writing this report. She is the guarantor for the study. GH, NT, TW, CS, JM, and $\mathrm{PC}$ participated in preparation of the treatment protocol and the training and supervision of the therapists. JM and PC were also responsible for training and supervising staff in administration of substance use measures. TW managed the London site. GH, SL, and TC trained the researchers in the psychiatric interviews, supervised and monitored standards of psychiatric interviewing and assessment throughout the trial. SL and TC also advised on diagnostic ratings and exclusions. RB was the trial manager. She supervised and coordinated recruitment, contributed to training of research staff, and was responsible for staff management and overall coordination of the study. EE replaced RB for the latter part of the study. GD was the trial statistician. He advised on randomisation and all statistical aspects of the trial, developed the analysis plan, and performed the statistical analyses. LD was the trial health economist.

Funding: The study was sponsored by the University of Manchester and funded by the UK Medical Research Council (grant no: G0200471) and the Department of Health. The sponsor and the funder of the study had no role in the study design, the data collection, analysis, and interpretation, or the reporting of this work, or the decision to submit the work for publication. All authors are independent of the funding source. All authors had full access to all study data.

Competing interests: All authors have completed the Unified Competing Interest form at www.icmje.org/coi_disclosure.pdf (available on request from the corresponding author) and declare: no support from any organisation for the submitted work; no financial relationships with any organisations that might have an interest in the submitted work in the previous 3 years; no other relationships or activities that could appear to have influenced the submitted work

Ethical approval: Ethical approval was obtained from the Cambridgeshire 4 research ethics committee (formerly the eastern multicentre research ethics committee; reference 03/5/045). All participants gave written informed consent before taking part.

Data sharing: We will be happy to make our dataset available to researchers once we have finished reporting our findings. Please contact the corresponding author at christine.barrowclough@manchester.ac.uk.

1 Regier DA, Farmer ME, Rae DS, Locke BZ, Keith SJ, Judd LL, et al. Comorbidity of mental disorders with alcohol and other drug abuse: results from the Epidemiologic Catchment Area (ECA) Study. JAMA 1990;264:2511-8.

2 Graham HL, Copello A, Birchwood MJ, Maslin J, McGovern D, Orford J, et al. The combined psychosis and substance use (COMPASS) programme: an integrated, shared care approach. In: Graham HL, Copello A, Birchwood MJ, Mueser KT, eds. Substance misuse in psychosis: approaches to treatment and service delivery. John Wiley \& Sons, 2003:106-20.

3 Weaver T, Rutter D, Madden P, Ward J, Stimson G, Renton A. Results of a screening survey for co-morbid substance misuse amongst patients in treatment for psychotic disorders: prevalence and service needs in an inner London borough. Soc Psychiatry Psychiatr Epidemiol 2001;36:399-406.

4 Dixon L, Haas G, Weiden PJ, Sweeney J, Frances AJ. Drug abuse in schizophrenic patients: clinical correlates and reasons for use. $\mathrm{Am}$. Psychiatry 1991;148:224-30.

5 Maslin I. Substance misuse in psychosis: contextual issues. In: Graham HL, Copello A, Birchwood MJ, Mueser KT, eds. Substance misuse in psychosis: approaches to treatment and service delivery. John Wiley \& Sons, 2003:3-23.

6 Cleary M, Hunt GE, Matheson SL, Siegfried N, Walter G. Psychosocial interventions for people with both severe mental illness and substance misuse. Cochrane Database Syst Rev 2008;1:CD001088.

7 Department of Health. Mental health policy implementation guide: dual diagnosis good practice guide. DH, 2002.

8 Ziedonis DM, Smelson D, Rosenthal RN, Batki SL, Green AL, Henry RJ, et al. Improving the care of individuals with schizophrenia and substance use disorders: consensus recommendations. J Psychiatr Pract 2005;11:315-406.

9 Baker A, Lewin T, Reichler H, Clancy R, Carr V, Garrett R, et al. Evaluation of a motivational interview for substance use within psychiatric in-patient services. Addiction 2002;97:1329-37.

10 Barrowclough C, Haddock G, Tarrier N, Lewis SW, Moring J, O’Brien R, et al. Randomised controlled trial of cognitive behavioural therapy plus motivational intervention for schizophrenia and substance use. Am J Psychiatry 2001;158:1706-13.

11 Miller WR, Rollnick S. Motivational interviewing: preparing people for change. 2nd ed. Guilford Press, 2002.

12 Martins RK, McNeil DW. Review of motivational interviewing in promoting health behaviours. Clin Psychol Rev 2010;29;283-93. ongoing management of the trial, and contributed to drafts of this report. $\mathrm{CB}$, the principal investigator, conceived of the study, prepared the protocol, contributed to the training and supervision of the therapists and supervision of the researchers, had overall responsibility for the day to day running of the study, interpreted the data, and took the lead on 
13 Hettema J, Steele J, Miller WR. Motivational interviewing. Annu Rev Clin Psychol 2005;1;91-111.

14 Stewart SH, Conrod PJ. Introduction to the special issue on state-ofthe-art cognitive-behavioral interventions for substance use disorders. J Cogn Psychother 2005;19:195-8.

15 Dutra L, Stathopoulu G, Basden SL, Leyro TM, Powers MB, Otto MW. A meta-analytic review of psychosocial interventions for substance use disorders. Am J Psychiatry 2008;165:179-87.

16 Denis C, Lavie E, Fatseas M, Auriacombe M. Psychotherapeutic interventions for cannabis abuse and/or dependence in outpatient settings. Cochrane Database Syst Rev 2006;3:CD005336.

17 Wykes T, Steel C, Everitt B, Tarrier N. Cognitive behaviour therapy for schizophrenia: effect sizes, clinical models, and methodological rigor. Schizophr Bull 2008;34:523-37.

18 National Institute for Health and Clinical Excellence. Schizophrenia: core interventions in the treatment and management of schizophrenia in adults in primary and secondary care (update). NICE, 2009.

19 Haddock G, Barrowclough C, Tarrier N, Moring J, O’Brien R, Schofield N, et al. Cognitive-behavioural therapy and motivational intervention for schizophrenia and substance misuse: 18 month outcomes of a randomised controlled trial. Br J Psychiatry 2003;183:418-26.

20 Boutron I, Moher D, Altman DG, Schulz KF, Ravaud P. Extending the CONSORT statement to randomized trials of nonpharmacologic treatment: explanation and elaboration. Ann Intern Med 2008;148:295-309.

21 Schulz K, Altman DG, Moher D, for the CONSORT Group. CONSORT 2010 statement: updated guidelines for reporting parallel group randomised trials. BMJ 2010;340:c332.

22 Moher D, Hopewell S, Schulz KF, Montori V, Gøtzsche PC Devereaux PJ, et al. CONSORT 2010 explanation and elaboration: updated guidelines for reporting parallel group randomised trials. BMJ 2010;340:c869.

23 First MB, Spitzer RL, Gibbon M, Williams JBW. Structured clinical interview for DSM-IV axis 1 disorders—clinician version (SCID-CV). American Psychiatric Press, 1997.

24 Barrowclough C, Haddock G, Beardmore R, Conrod P, Craig T, Davies L, et al. Evaluating integrated MI and CBT for people with psychosis and substance misuse: recruitment, retention and sample characteristics of the MIDAS trial. Addict Behav 2009;34:859-66.

25 Haddock G, Beardmore R, Earnshaw P, Fitzsimmons M, Nothard S, Butler R, et al. Assessing fidelity for integrated motivational interviewing and CBT therapy for psychosis and substance use: the MI-CTS fidelity scale. J Ment Health (submitted 2010).

26 Saunders JB, Aasland OG, Babor TF, de la Fuente JR, Grant M. Development of the Alcohol Use Identification Test (AUDIT): WHO collaborative project on early detection of persons with harmful alcohol consumption-II. Addiction 1993;88:791-804.

27 Babor T, Higgins-Biddle JC, Saunders JB, Monteiro MG. The alcohol use disorders identification test: guidelines for use in primary care. 2nd ed. World Health Organization, 2001.

28 Skinner HA. The drug abuse screening test. Addict Behav 1982;7:363-71.

29 Alexander D, Leung P. The Marijuana Screening Inventory (MSI-X): concurrent, convergent and discriminant validity with multiple measures. Am J Drug Alcohol Abuse 2006;32:351-78.
30 Hogan TP, Awad AG, Eastwood R. A self-report scale predictive of drug compliance in schizophrenics: reliability and discriminative validity. Psychol Med 1983;13:177-83.

31 Cicchetti D. Guidelines, criteria and rules of thumb for evaluating normed and standardized assessment instruments in psychology. Psychol Assess 1994;6:284-90.

32 Rollnick S, Heather N, Gold R, Hall W. Development of a short 'readiness to change' questionnaire for use in brief opportunistic interventions among excessive drinkers. Br JAddict 1992;87:743-54.

33 Blanchard KA, Morgenstern J, Morgan TJ, Labouvie EW, Bux DA. Assessing consequences of substance use: psychometric properties of the Inventory of Drug Use Consequences. Psychol Addict Behav 2003;17:328-31.

34 Sobell LC, Sobell MB. Timeline follow back: a technique for assessing self-reported alcohol consumption. In: Litten RZ, Allen JP, eds. Measuring alcohol consumption: psychosocial and biochemical methods. Humana Press Inc, 1992:41-72.

35 Carey KB. Reliability and validity of the time-line follow-back interview among psychiatric outpatients: a preliminary report. Psychol Addict Behav 1997;11:26-33.

36 Carey KB, Carey MP, Maisto SA, Henson JM. Temporal stability of the timeline follow-back interview for alcohol and drug use with psychiatric outpatients. J Stud Alcohol 2004;65:774-81.

37 Stasiewicz P, Vincent PC, Bradizza CM, Connors GJ, Maisto SA, Mercer ND. Factors affecting agreement between severely mentally ill alcohol abusers' and collaterals' reports of alcohol and other substance use. Psychol Addict Behav 2008;22:78-87.

38 Drake RE, Mueser KT, McHugo GJ. Clinician rating scales: alcohol use scale (AUS), drug use scale (DUS), and substance abuse treatment scale (SATS). In: Sederer LI, Dickey B, eds. Outcomes assessment in clinical practice. Williams \& Wilkins, 1996:113-6.

39 Kay S, Fiszbein A, Opler L. The positive and negative syndrome scale (PANSS) for schizophrenia. Schizophr Bull 1987;13:261-76.

40 American Psychiatric Association. Diagnostic and statistical manual of mental disorders (DSM-IV). 4th ed. American Psychiatric Association, 1994

41 White H. Maximum likelihood estimation of misspecified models Econometrica 1982;50:1-25.

42 Miller WR, Wilbourne PL. Mesa Grande: a methodological analysis of clinical trials of treatments for alcohol use disorders. Addiction 2002;97:265-77.

43 Kaner EF, Dickinson HO, Beyer FR, Campbell F, Schlesinger C Heather $\mathrm{N}$, et al. Effectiveness of brief alcohol interventions in primary care populations. Cochrane Database Syst Rev 2007;2:CD004148.

44 Edwards J, Elkins K, Hinton M, Harrigan S, Donovan K, Athanasopoulos $\mathrm{O}$, et al. Randomised controlled trial of a cannabis focused intervention for young people with first-episode psychosis. Acta Psychiatr Scand 2006;114:109-17.

45 Baker A, Bucci S, Lewin TJ, Kay-Lambkin F, Constable PM, Carr V]. Cognitive-behavioural therapy for substance use disorders in people with psychotic disorders: randomised controlled trial. Br J Psychiatry 2006;188:439-48.

46 Bellack AS, Bennett ME, Gearon JS, Brown CH, Yang Y. A randomized clinical trial of a new behavioural treatment for drug abuse in people with severe and persistent mental illness. Arch Gen Psychiatry 2006;63:426-32.

Accepted: 16 September 2010 